EXPERIMENTAL AND THEORETICAL DETERMINATION OF HEAVY OIL VISCOSITY UNDER RESERVOIR CONDITIONS

Annual Report

October 2000-September 2001

By

Jorge Gabitto

Maria Barrufet

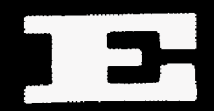

Date Published: March 2002

Work Performed Under Contract No. DE-FG26-99FT40615

Prairie View A\&M University

Prairie View, Texas

National Energy Technology Laboratory National Petroleum Technology Office U.S. DEPARTMENT OF ENERGY Tulsa, Oklahoma 


\section{DISCLAIMER}

This report was prepared as an account of work sponsored by an agency of the United States Government. Neither the United States Government nor any agency thereof, nor any of their employees, makes any warranty, expressed or implied, or assumes any legal liability or responsibility for the accuracy, completeness, or usefulness of any information, apparatus, product, or process disclosed, or represents that its use would not infringe privately owned rights. Reference herein to any specific commercial product, process, or service by trade name, trademark, manufacturer, or otherwise does not necessarily constitute or imply its endorsement, recommendation, or favoring by the United States Government or any agency thereof. The views and opinions of authors expressed herein do not necessarily state or reflect those of the United States Government.

This report has been reproduced directly from the best available copy. 
Experimental and Theoretical Determination of Heavy Oil Viscosity Under Reservoir Conditions

\author{
By \\ Jorge Gibitto \\ Maria Barrufet
}

March 2002

Work Performed Under DE-FG26-99FT40615

\author{
Prepared for \\ U.S. Department of Energy \\ Assistant Secretary for Fossil Energy \\ Jerry Casteel, Project Manager \\ National Petroleum Technology Office \\ P.O. Box 3628 \\ Tulsa, OK 74101
}

Prepared by

Prairie View A\&M University

Office of Sponsored Programs

Box 667

Prairie View, TX 77446 


\section{EXPERIMENTAL AND THEORETICAL DETERMINATION OF HEAVY}

OIL VISCOSITY UNDER RESERVOIR CONDITIONS

\section{TABLE OF CONTENTS}

\section{ABSTRACT}

TABLE OF CONTENTS

STATEMENT OF WORK

$\begin{array}{ll}\text { TECHNICAL DESCRIPTION } & 2\end{array}$

Introduction $\quad 2$

$\begin{array}{ll}\text { Objectives } & 2\end{array}$

An Automated Data Quality Control Procedure to

Screen Crude Oil Viscosity Data 3

Abstract 3

Introduction 4

Viscosity Correlations $\quad 5$

Reservoir Fluid Studies for Reservoir Engineering 5

Data Preparation and Data Screening Routine 7

Data Screening Results 9

Modification of Pedersen's Model for Saturated

$\begin{array}{lr}\text { Crude Oil Viscosity } & 9\end{array}$

$\begin{array}{ll}\text { Viscosity Correlations } & 10\end{array}$

Model Development $\quad 12$

Results 16

$\begin{array}{ll}\text { Conclusions } & 17\end{array}$

$\begin{array}{ll}\text { FUTURE WORK } & 17\end{array}$

$\begin{array}{ll}\text { NOMENCLATURE } & 18\end{array}$

$\begin{array}{ll}\text { REFERENCES } & 21\end{array}$

$\begin{array}{lr}\text { TABLES AND FIGURES } & 23\end{array}$ 



\title{
EXPERIMENTAL AND THEORETICAL DETERMINATION OF HEAVY OIL VISCOSITY UNDER RESERVOIR CONDITIONS
}

\begin{abstract}
The USA deposits of heavy oils and tar sands contain significant energy reserves. Thermal methods, particularly steam drive and steam soak, are used to recover heavy oils and bitumen. Thermal methods rely on several displacement mechanisms to recover oil, but the most important is the reduction of crude viscosity with increasing temperature.

The main objective of this research is to propose a simple procedure to predict heavy oil viscosity at reservoir conditions as a function of easily determined physical properties. This procedure will avoid costly experimental testing and reduce uncertainty in designing thermal recovery processes.

We reviewed critically the existing literature choosing the most promising models for viscosity determination in our first report. In this second part we modified an existing viscosity correlation, Pedersen et al. ${ }^{1}$, based on the corresponding states principle in order to fit more than two thousand commercial viscosity data. We collected data for black oil samples in absence of compositional data. The data were screened for inconsistencies resulting from experimental error. A procedure based on the monotonic increase or decrease of key variables was implemented to carry out the screening process. A simple procedure is proposed to calculate black oil viscosity from common experimental information such as, boiling point, API gravity and molecular weight.

Next step will involve the extension of the modified procedure to oil samples where compositional data are available.
\end{abstract}





\section{STATEMENT OF WORK (SOW)}

Under this Statement of Work (SOW), Dr. Jorge Gabitto from the Chemical Engineering Department at Prairie View A\&M University (PVAMU), Dr. Maria Barrufet from the Petroleum Engineering Department at Texas A\&M University (TAMU) and Dr. Rebecca Bryant from Bio-Engineering International Inc. (BEI) will conduct research and training in the area of transport and thermodynamic properties determination for heavy oils. Chevron Oil Company will provide consulting and heavy oil samples to be used in the project.

A research project is proposed to develop theoretical models, computer algorithms, and measure experimentally transport and thermodynamic properties of heavy oils. Model evaluation will be an important part of the project.

This research will involve training of graduate and undergraduate students in state of the art techniques. Technology transfer of the results generated by the project will be achieved through Dr. Bryant's efforts and publications in refereed journals.

Dr. Gabitto will act as coordinator of the research team and he will be responsible by most of the theoretical program. Dr. Barrufet will be Co-Principal Investigator, and she will be responsible for the experimental part. Dr. Bryant will advise the research team, and she will be responsible for transferring the project's findings to small independent producers. 


\section{TECHNICAL DESCRIPTION}

\section{Introduction}

The viscosity of heavy oils is a critical property in predicting oil recovery. Viscosity reduction and thermal expansion are the key properties to increase productivity of heavy oils. Thermal methods are pivotal in successfully producing oils with an API gravity of less than 20 degrees. These recovery methods may involve steam, hot water injection, and in-situ combustion ${ }^{2}$. For improving heavy oil recovery, steam injection has proven to be the premier approach for both stimulating producing wells and displacing oil in the reservoir. The amount of high viscosity oil produced by steam methods is increasing annually throughout the world ${ }^{3}$.

Modern reservoir engineering practices require accurate information of thermodynamic and transport fluid properties together with reservoir rock properties to perform material balance calculations. These calculations lead to the determination (estimation) of the initial hydrocarbons (oil and gas) in-place, the future reservoir performance, optimal exploration and production schemes, and the ultimate hydrocarbon recovery. The technical and economic viability of steam flooding processes have been established by laboratory and field studies of rock formations and crude oils ${ }^{3}$. Extensive knowledge of fluid properties is required to properly develop a steam flooding strategy.

Reservoir simulators are routinely used to predict and optimize oil recovery from oil fields. These simulators require as input properties of the reservoir fluids as a function of pressure, temperature and composition. The accuracy of the fluid properties can decisively affect the results of the simulation. Among the required fluid properties are: phase densities, phase viscosities, formation volume factors $\left(\mathrm{B}_{\mathrm{O}}\right)$, and dissolved gas-oil ratios. The proposed research program includes the measurement and thermodynamic modeling of these properties.

\section{Objectives}

The objectives of this research program are to determine viscosity and other required thermodynamic properties of heavy crude oil mixtures at various temperatures with and without steam at pressures and temperatures characteristic of steam flooding processes. 
This research program has been divided in a theoretical and an experimental part. The theoretical part involves a critical literature review followed by development of a model based on the corresponding states theory. The experimental part involves measurement of viscosity of hydrocarbons mixtures and heavy oils under different temperatures and pressures characteristic of real reservoir conditions. Finally comparison between predicted and measured mixtures viscosity will be done.

The first report presented the results of our literature review and data from the first experiments completed. The modification of Pedersen et al. ${ }^{1}$ viscosity correlation for black oils is presented here. A screening process for the experimental data used is also presented.

\section{An Automated Data Ouality Control Procedure to Screen Crude Oil Viscosity Data}

\section{Abstract}

Most correlations for crude oil viscosity require additional tuning to provide acceptable predictions for a given reservoir fluid. Before recalibrating these correlations, data must be quality controlled to ensure suitable performance of regression procedures. For large data sets this data preprocessing could become tedious and laborious unless a systematic and automated consistency check is used.

For this study, we had a database of almost 3,000 records of PVT properties and black oil viscosity data, coming from 324 differential liberation tests performed in commercial laboratories.

We have developed a procedure to "clean up" the data on a test basis, before processing it with a regression routine. We individually screened each test, identified outlying observations and removed those from the regression calculations.

The criteria used to discard data relied on the numerical evaluation of the first derivative of selected functions of one variable. These functions should either always increase or decrease, when the physical behavior is predicted appropriately. For example oil viscosity (observed function) should always increase as the pressure in the differential liberation tests is decreased. Forward and backward derivatives were used to account for 
the end points. The filtered data resulting from this quality control process consisted of 2,324 observations.

The data were used to adapt two compositional viscosity models, Pedersen et al. ${ }^{1}$ and Lohrenz, Bray and Clark ${ }^{4}$ (LBC), so that these models can be used for black oil systems when compositional data are missing. The oil viscosity ranged from 0.18 to $78 \mathrm{cp}$, with pressure from 63 to $4,014 \mathrm{psia}$ and temperature from $80^{\circ} \mathrm{F}$ to $288^{\circ} \mathrm{F}$. The oil API gravity ranged from 18.6 to 53.6. These models were validated against an independent data set consisting of 150 observations. The two models had lower statistical errors than current correlations.

\section{Introduction}

Crude oil viscosity is important in the calculation of two-phase flow, gas/liquid flowing pressure traverses, tubing-string design, gas-lift design, and pipeline design. Most important of all, it is needed to calculate the recovery of the oil either from natural depletion or from recovery techniques such as water-flooding and gas-injection processes.

Live oil viscosity is a strong function of pressure, temperature, oil gravity, gas gravity, gas solubility, molecular sizes, and composition of the oil mixture. The variation of viscosity with molecular structure is not well known because of the complexity of crude oil systems. However, paraffin hydrocarbons do exhibit a regular increase in viscosity as the size and complexity of molecules increases.

Crude oil viscosity correlations are usually developed for three situations: above the bubble-point pressure, at and below the bubble-point pressure, and for dead oil ${ }^{5}$. Dead oil is oil without gas in solution at atmospheric pressure. Above the bubble-point, the composition of the oil mixture is constant and the viscosity changes result from compressibility: The fluid becomes heavier and its viscosity increases. At some point during production, the pressure drops below the bubble-point value, gas comes out of solution, and the oil composition changes continuously. The oil becomes heavier and more viscous, and two phases will flow in the reservoir. 


\section{Viscosity Correlations}

Numerous viscosity-correlation methods have been proposed. None, however, has been used as a standard method in the oil industry. Since the crude oil composition is complex and often undefined, many viscosity estimation methods are geographically dependent. Most correlation methods can be categorized either as 'black oil' or as compositional.

Black oil correlations predict viscosities from available field-measured variables by fitting of an empirical equation. The correlating variables traditionally include a combination of solution gas/oil ratios $\left(R_{s}\right)$, bubble-point pressure, oil API gravity, temperature, specific gas gravity, and the dead oil viscosity or the viscosity at the bubblepoint. Chew and Connally ${ }^{5}$, Beggs and Robinson ${ }^{6}$, Khan et al. ${ }^{7}$, Kartoatmodjo and Schmidt $^{8}$ and Petrosky ${ }^{9}$ correlated oil viscosity with temperature, pressure, oil gravity and solution gas/oil ratio.

The second method derives mostly from the principle of corresponding states and its extensions. Lohrenz et al. ${ }^{4}$, Ely and Hanley ${ }^{10}$, Pedersen and Fredenslund ${ }^{11}$, Pedersen et al. ${ }^{1}$, and Monnery et al. ${ }^{12}$ are among the researchers following this trend. Lohrenz et al. ${ }^{4}$ and Pedersen et al. ${ }^{1}$ are probably the most common methods implemented in the majority of the commercial compositional reservoir simulators.

Methods based upon the corresponding states theory predict the crude-oil viscosity as a function of temperature, pressure, composition of the mixture, pseudo-critical properties of the mixture, and the viscosity of a reference substance evaluated at a reference pressure and temperature.

A thorough description of the viscosity prediction methods to be used in this research will be shown in the next section dealing with the modification to Pedersen et al. ${ }^{1}$ method.

\section{Reservoir Fluid Studies for Reservoir Engineering}

A black oil reservoir fluid study consists of a series of laboratory procedures designed to provide values of the physical properties needed in the calculation method known as material balance calculations. The experiments are performed with live oil samples at pressures above and below the bubble-point pressure. Sampling procedures are discussed in detail elsewhere ${ }^{13}$. In general two types of samples are obtained. For bottom-hole 
samples, or subsurface samples, the well is shut in and the liquid at the bottom of the wellbore is sampled. In the other sampling method, production rates are carefully monitored and the gas and liquid from the separators are recombined at the producing volumetric gas/oil ratio. Oil reservoirs must be sampled before the reservoir pressure drops below the bubble-point pressure of the oil, since at pressures below that no sampling method will give a sample representative of the original reservoir mixture.

Determining the composition of all chemical species present in the black oil is virtually impossible and impractical. In the majority of cases the composition of the light components is determined, from methane to hexane, and all the heavier components are grouped together in a plus fraction commonly labeled as the heptane plus fraction.

Material balance calculations are in fact volumetric calculations in which the reservoir fluids volumes filling the pore space are determined as a function of pressure. Corrections to account for rock compressibility effects and water encroachment are also included. The reservoir is considered as a tank filled with oil, gas and water. As production takes place these volumes change as illustrated in Fig. 1.

Standard reservoir PVT fluid studies are designed to simulate processes at which oil and gas displace from the reservoir to surface.

In a constant composition expansion test (CCE) a sample of the reservoir fluid is placed in a variable volume PVT cell at the reservoir temperature. The pressure is adjusted at or above the original reservoir pressure. Pressure is reduced by incrementally increasing the cell volume, and pressure/volume pairs are recorded and plotted. The pressure at which the slope changes is the bubble-point pressure and the volume at this point is the bubble-point volume. All of the liberated gas remains in contact with the oil until the two phases reach equilibrium, neither gas or liquid is removed from this cell during the process; therefore, the overall composition remains constant. This test also provides isothermal oil compressibility. Fig. 2 is a sketch of this laboratory process.

The production path of reservoir fluids from the reservoir to surface is simulated in the laboratory by a set of stage-wise flashings of the live oil at reservoir temperature. These tests are labeled differential liberation tests (DL). Here the sample is placed in a PVT cell at its bubble-point pressure. Then, pressure is reduced by incremental increases in the cell volume. The difference in this test is that all the gas liberated is expelled from 
the cell while the pressure is held constant by using a dual-cell arrangement. The gas is collected, and its quantity and specific gravity are measured. During this process the oil volumes and the amount of gas released are measured and used to determine oil and gas formation volume factors ( $B_{o}$, and $B_{g}$ ) and solution gas/oil ratios as a function of pressure $R_{s}$. Fig. 3 shows a schematic of the differential liberation process that ends at atmospheric pressure. The liquid phase is called 'dead' oil. The temperature is then reduced to $60^{\circ} \mathrm{F}$ and the volume of this oil is identified as residual oil. Table 1 shows one out of the 324 differential liberation (DL) sets used in this study, and Table 2 shows the corresponding viscosity data.

The oil formation volume factor $B_{o}$ gives an idea of the shrinkage experienced by a unit volume of reservoir as it goes from reservoir pressure and temperature to standard pressure and temperature, or stock tank conditions, while the solution gas/oil ratio at a given pressure provides the amount of dissolved gas (which will be eventually produced) expressed as standard cubic feet per barrel of oil at standard conditions.

The oil viscosity is usually measured in a rolling-ball viscometer or a capillary viscometer, either designed to simulate differential liberation. The composition of the oil sample is not measured in either of the DL stages. The viscosity measured at the lowest pressure usually has the highest uncertainty.

\section{Data Preparation and Data Screening Routine}

The viscosity correlations proposed are expressed as functions of other variables or properties that are either measured or calculated from correlations. These variables include oil density, molecular weight, pseudo-critical properties, pressure and temperature, among others. The correlation will be meaningless if the quality of these variables, or the quality of the data, is questionable. In that case one may be attempting to calculate parameters by fitting errors.

During the DL process the oil becomes heavier and some physical properties should monotonically increase as the pressure decreases. These include $V_{c m}, T_{c m}, T_{b}, M_{w m}$, oil density and oil viscosity. The mixture critical properties are not known and rather pseudo-critical properties are used, but they should follow the same trend as the true critical. These pseudo-critical properties and molecular weights are not actually 
measured but correlated to measurable variables such as the oil density and the normal boiling point. For lighter oils the critical pressure may go through a maximum before it starts decreasing, as the oil becomes heavier ${ }^{14}$.

Most correlations for crude oil viscosity require additional tuning to provide acceptable predictions for a given reservoir fluid. Before recalibrating these correlations, data must be quality controlled to ensure suitable performance of regression procedures. For large data sets this data preprocessing could become tedious and laborious unless a systematic and automated consistency check is used.

For this study, we had a database of almost 3,000 records of PVT properties and black oil viscosity data, coming from 324 differential liberation tests performed in commercial laboratories.

Sometimes the data may be of good quality but the correlation may be applied beyond its range. We verified that $M_{w m}, T_{c m}$ and $V_{c m}$ were monotonically increasing. The correlations used provide the correct behavior for oil specific gravities above 0.6. Since we had oils with lower specific gravities below 0.6 we extrapolated the correlations following a consistent trend as indicated in Fig. 4.

We have developed a procedure to "clean up" the data on a DL test basis, before processing it with a regression package. We individually screened each test, identified outlying observations and removed those from the regression calculations.

The criteria used to discard data relied on the numerical evaluation of the first derivative of selected functions of one variable. These functions should either always increase or decrease, when the physical behavior is predicted appropriately. For example oil viscosity (observed function) should always increase as the pressure in the differential liberation tests is decreased. Forward and backward derivatives were used to account for the end points. The filtered data resulting from this quality control process consisted of 2,324 observations.

The data were classified according to test number. Each DL is characterized by temperature and API gravity of the residual oil. The highest pressure in every set corresponds to the bubble-point pressure at that temperature. This pressure is extracted and written to a file for use in the correlations for solution gas/oil ratio and formation volume factor. The viscosity data were contained in separate files and even though these 
corresponded to the same DL tests, some viscosity measurements were missing or were done at different pressures. Assembling of these two sets of files was done one a one-to one match. The missing pair was removed from either set and stored in a separate file.

Each matched DL and viscosity set contained between 6 and 10 observations at declining pressures. Properties were evaluated for these observations and stored.

Forward and backward derivatives were used for viscosity and oil density versus pressure. The first derivative of these functions should always be negative. If a point violated this monotony criterion all measured properties at that pressure were discarded.

Occasionally the oil density exhibited a consistent behavior within some acceptable scatter and the data points passed the consistency test. However, if derived properties $\left(M_{w m}, T_{c m}, V_{c m}\right)$ magnified the inconsistency, these were included in the list of checking variables and provided a more rigorous screening.

The number of points left in a DL set should be at least 4. Even if these appeared to be correct, the fact that the remaining points were discarded made the test questionable.

\section{Data Screening Results}

Figures 5 to 7 indicate examples of removed data. You can find deviations from a monotonic trend for different properties. These deviations are caused by experimental and/or human errors. With all the cleaned data we proceeded to develop correlations for the viscosity based upon the modified Pedersen ${ }^{1}$ and Lohrenz ${ }^{4}$ models. Additionally we proposed new correlations for solution gas-oil ratios and formation volume factors to be used in these models.

\section{Modification of Pedersen's Model for Saturated Crude Oil Viscosities}

This section presents a modification of Pedersen's corresponding states compositional viscosity model that enables viscosity prediction for black oil systems when there are no compositional data available. This model can be easily implemented in any reservoir simulation software, it can be easily tuned, and it provides better estimates of oil viscosity than the existing correlations. 
Viscosity from 324 sets of differential liberation data consisting of 2343 observations covering a wide range of pressure, temperature, and oil density were used to develop the correlation. This correlation retains most of the functional form of Pedersen's model. These modifications include (1) use of n-decane as the reference fluid, (2) consider the oil mixture as a single pseudo-component with molecular weight and critical properties correlated to its density, and (3) addition of a functional dependence to solution gas/oil ratio and gas-specific gravity. The average error over 2343 viscosity observations was $0.9 \%$. The model was tested against a second data set consisting of 150 observations and the average error was $0.7 \%$.

The predictions were compared with those predicted from the correlations of Khan et $a l .^{7}$ and of Petrosky ${ }^{9}$ that are applicable to the experimental conditions of our data sets. These average errors for these correlations were $-28 \%$ and $4.9 \%$ respectively for the first data set; and $-60.8 \%$ and $-1.4 \%$ for the second data set.

\section{Viscosity Correlations}

Numerous viscosity-correlation methods have been proposed. None, however, has been used as a standard method in the oil industry. Most correlation methods can be categorized either as 'black oil' or as compositional.

Black oil correlations predict viscosities from available field-measured variables by fitting of an empirical equation. The correlating variables traditionally include a combination of solution gas/oil ratios $\left(R_{s}\right)$, bubble-point pressure, oil API gravity, temperature, specific gas gravity, and the dead oil viscosity or the viscosity at the bubblepoint.

The second method derives mostly from the principle of corresponding states and its extensions. Methods based upon the corresponding states theory predict the crude-oil viscosity as a function of temperature, pressure, composition of the mixture, pseudocritical properties of the mixture, and the viscosity of a reference substance evaluated at a reference pressure and temperature.

Lohrenz et al. ${ }^{4}$ published the now well-known LBC correlation suitable for gases and light oils. The LBC correlation is a fourth-degree polynomial in the pseudo-reduced density of the mixture and this makes it very sensitive to this variable. 


$$
\left[\left(\mu-\mu^{*}\right) \xi+10^{-4}\right]^{1 / 4}=\sum_{i=1}^{5} a_{i} \rho_{r}{ }^{i-1}
$$

Here $\mu^{*}$ is the low-pressure gas mixture viscosity, and $\xi$ is the viscosity-reducing parameter, which is defined as,

$$
\xi=T_{c m}{ }^{1 / 6} M_{w m}{ }^{1 / 2} P_{c m}{ }^{2 / 3}
$$

Ely and Hanley ${ }^{10}$ (1981) proposed the following extended corresponding states model:

$$
\begin{aligned}
& \eta_{\mathrm{i}}(\rho, \mathrm{T})=\eta_{\mathrm{o}}\left(\rho_{\mathrm{h}_{\mathrm{i}, \mathrm{o}}}, \mathrm{T} / \mathrm{f}_{\mathrm{i}, \mathrm{o}}\right)\left(M_{i} / M_{o}\right)^{1 / 2} \mathrm{hi}, \mathrm{o} f \mathrm{fi}, \mathrm{o}^{-2 / 2} \\
& \mathrm{~h}_{i, o}=\mathrm{h}_{i, o}\left(\rho_{\mathrm{c}, \mathrm{i}} / \rho_{\mathrm{c}, \mathrm{o}}\right) \varphi_{\mathrm{i}, \mathrm{o}} \\
& \mathrm{f}_{i, b}=(\mathrm{Tc}, \mathrm{i} / \mathrm{Tc}, \mathrm{o}){ }_{\theta \mathrm{i}, \mathrm{o}}
\end{aligned}
$$

where $\theta_{i, o}$, and $\varphi_{i, o}$ are shape factors depending on the chemical components. Viscosity calculations require correlations for a reference fluid viscosity and density along with critical properties values, acentric factor and molar mass. Methane was selected as a reference fluid because of the availability of highly accurate data. A problem using methane is its high freezing point $\left(\mathrm{T}_{\mathrm{r}}=0.48\right)$, which is well above the reduced temperatures of other fluids in the liquid state. In order to overcome this difficulty they extrapolated the density correlation for methane and added an empirical correlation for non-correspondence and extended the viscosity correlation of Henley et al. ${ }^{15}$ (1975).

Pedersen et al. ${ }^{1}$ introduced a third parameter $(\alpha)$ to correct for this deviation from the conventional corresponding states principle. This term accounts for the molecular size and density effects on viscosity. Their model eliminates the iterative procedure in Ely and Hanley ${ }^{10}$ and performs a direct calculation of the viscosity. 
These authors proposed a similar approach for hydrocarbon and crude oil viscosities:

$$
\eta_{\mathrm{x}}(\mathrm{P}, \mathrm{T})=\left(\mathrm{T}_{\mathrm{c}, \mathrm{x}} / \mathrm{T}_{\mathrm{c}, \mathrm{o}}\right)^{-1 / 6}\left(\mathrm{P}_{\mathrm{c}, \mathrm{x}} / \mathrm{P}_{\mathrm{c}, \mathrm{o}}\right)^{2 / 3}\left(\mathrm{M}_{\mathrm{i}} / \mathrm{M}_{\mathrm{o}}\right)^{1 / 2} \alpha_{\mathrm{TG}, \mathrm{x}} / \alpha_{\mathrm{TG}, \mathrm{o}} \eta_{\mathrm{o}}\left(\mathrm{P}_{\mathrm{o}}^{*}, \mathrm{~T}_{\mathrm{o}}^{*}\right)(6),
$$

and,

$$
\begin{aligned}
& \mathrm{T}_{\mathrm{o}}^{*}=\left(\mathrm{T}_{\mathrm{c}, \mathrm{x}} / \mathrm{T}_{\mathrm{c}, \mathrm{o}}\right)\left(\alpha_{\mathrm{TG}, \mathrm{o}} / \alpha_{\mathrm{TG}, \mathrm{x}}\right) \\
& \left.\mathrm{P}_{\mathrm{o}}^{*}=\left(\mathrm{P}_{\mathrm{c}, \mathrm{x}} / \mathrm{P}_{\mathrm{c}, \mathrm{o}}\right){\left(\alpha_{\mathrm{TG}, \mathrm{o}} / \alpha_{\mathrm{TG}, \mathrm{x}}\right)} /{ }\right)
\end{aligned}
$$

where $\alpha_{\mathrm{TG}}$ is the Tham-Gubbins ${ }^{16}$ (1971) rotational coupling coefficient.

According to Pedersen et al. ${ }^{1}$ the problems associated with representing poly-disperse mixtures (such as crude oils) are associated with the computation of average molar mass. Their results indicated that larger molecules should make a greater contribution to viscosity than the smaller ones. The mixture molar mass was calculated empirically as,

$$
\mathrm{M}_{\mathrm{n}}=\mathrm{M}_{\mathrm{n}}+\mathrm{b}_{1}\left(\mathrm{M}_{\mathrm{w}}-\mathrm{M}_{\mathrm{n}}\right)
$$

where $b_{1}$ is an empirical constant obtained by fitting experimental data, $\alpha_{\mathrm{TG}}$ was determined from the molar mass and reduced density. The mixture viscosity was calculated from eqn. (4) with the mixing rules provided for pseudo-critical properties.

Pedersen and Fredenslund ${ }^{17}$ (1986) extended Pedersen et al. ${ }^{1}$ method to mixtures with $T_{\mathrm{T}}$ below 0.4 (below methane freezing point) by modifying the equations for $\mathrm{M}_{n}$ and $\alpha_{\mathrm{TG}}$.

\section{Model Development}

Since most of the features from our correlation resemble Pedersen et al. ${ }^{1}$ model we rewrite their model here.

$$
\mu_{m}(P, T)=\left(\frac{T_{c m}}{T_{c o}}\right)^{\alpha_{1}}\left(\frac{P_{c m}}{P_{c o}}\right)^{\alpha_{2}}\left(\frac{M W_{m}}{M W_{o}}\right)^{\alpha_{3}}\left(\frac{\alpha_{m}}{\alpha_{o}}\right) \mu_{o}\left(P_{o}, T_{o}\right),
$$

where the coefficients $\alpha_{1}, \alpha_{2}$ and $\alpha_{3}$ in Pedersen's model are $-1 / 6,2 / 3$ and $1 / 2$ respectively.

$$
\begin{aligned}
& \alpha_{m}=1.000+7.378 \times 10^{-3} \rho_{r o}^{1.847} M W_{m}^{0.5173} \\
& \alpha_{o}=1.000+0.031 \rho_{r o}^{1.847}
\end{aligned}
$$

Here, $\rho_{r o}$ is the reduced density of the reference fluid. Pedersen et al ${ }^{-1}$ used methane as the reference fluid. They used a BWR-equation in the form suggested by McCarty ${ }^{18}$ to 
evaluate the density of methane. This density is evaluated at a reference pressure and temperature as indicated in Eqn. (13)

$$
\rho_{r o}=\frac{\rho_{o}\left(\frac{P P_{c o}}{P_{c m}}, \frac{T T_{c o}}{T_{c m}}\right)}{\rho_{c o}}
$$

the pressures and temperatures at which the reference viscosity $\left(\mu_{0}\right)$ is evaluated are given by,

$$
P_{o}=\frac{P P_{c o} \alpha_{o}}{P_{c m} \alpha_{m}} \quad \text { and } \quad T_{o}=\frac{T T_{c o} \alpha_{o}}{T_{c m} \alpha_{m}}
$$

The critical temperature and pressure are found using the mixing rules suggested by Mo and Gubbins ${ }^{19}$ using the composition of the oil mixture. The method is highly sensitive to the characterization of the heavy fraction, usually known as the $\mathrm{C}_{7}^{+}$fraction. Our objective was to extend this model to black oil mixtures for which we do not have compositional information.

The limitation of methane as the reference substance is that when the reduced temperature of methane is below 0.4, it will freeze. This is above the reduced temperatures for most reservoir fluids. Pedersen et al. ${ }^{1}$ solved this problem by modifying the viscosity model of Hanley et al.$^{15}$, while Monnery et al. ${ }^{12}$ suggested using propane as a reference fluid.

To use Eqn. (10) we needed to find simplified expressions for the molecular weight $\left(M W_{m}\right)$, critical temperature and pressure $\left(T_{c m}\right.$, and $\left.P_{c m}\right)$ of the mixture, and for the density and viscosity of the reference fluid. We initially used methane as the reference fluid, but rather than implementing Pedersen's modifications, which are tedious and add additional complexity to the model, we decided to use an alternative reference fluid. We selected $\mathrm{n}$-decane for this purpose.

The viscosity and density data for $n$-decane were taken from various sources reported by Geopetrole ${ }^{20}$ covering pressures from 14.7 psia to 7325 psia and temperatures from $492^{\circ} \mathrm{F}$ to $762^{\circ} \mathrm{F}$. The density and viscosity of n-decane were fitted as a function of $P$ and $T$ using a stepwise regression procedure and the statistical software SAS $^{21}$. The density, in $\mathrm{lb} / \mathrm{ft}^{3}$, is calculated by 


$$
\rho_{\mathrm{C} 10}=\exp \left(-1847.7998 \times \mathrm{T}^{-1}+168.1906 \times \mathrm{T}^{-1 / 2}+1.5043 \times 10^{-8} \mathrm{TP}\right) .
$$

while the viscosity, in $\mathrm{cp}$, is given by,

$$
\begin{aligned}
\mu_{\mathrm{C} 10}= & 50991.51 \frac{1}{\mathrm{~T}}+2321.5418 \times \mathrm{T}^{-1 / 3}-8775.2881 \times \mathrm{T}^{-1 / 2}+0.4775 \frac{\mathrm{P}}{\mathrm{T}} \\
& -0.001272 \times \mathrm{P}-6.7057 \times 10^{-9} \times \mathrm{T}^{3}+8.87 \times 10^{-7} \times \mathrm{PT}
\end{aligned}
$$

The correlation coefficient for Eqn. (6) is $R^{2}=0.9996$ with minimum and maximum errors of $-1.47 \%$ and $+1.82 \%$ respectively. Eqn. (7) has a correlation coefficient of $R^{2}=$ 0.9998 and gives minimum and maximum errors of $-3.11 \%$ and $+8.21 \%$ respectively. The pressures and temperatures that appear in Eqns. (15) and (16) are in psia and Ranking degrees, respectively.

The specific gravity of the oil was evaluated from a material balance using the reported values of formation volume factor $\left(B_{o}\right)$, solution gas/oil ratio $\left(R_{s}\right)$, and gas specific gravity according to $\mathrm{McCain}^{22}$. The reported specific gravity of the gas was for the separator at 100 psia rather than at atmospheric pressure, however; the error introduced in the determination of specific gravity of the oil is negligible.

The oil mixture was lumped into a single pseudo-component for which the critical temperature, the critical pressure, and the molecular weight were correlated to the oil specific gravity.

Most correlations for the critical properties require at least two properties from the molecular weight, the density, and the normal boiling point. We had only one of these variables. To overcome this problem we assumed that for most oils the percentage of paraffinic compounds dominates and in that case we correlated the normal boiling versus specific gravity of oil at reservoir conditions $\left(\gamma_{0, \mathrm{R}}\right)$. Once this was determined the molecular weight was correlated to the normal boiling point in $\mathrm{R}$. The data to develop these correlations were reported by $\mathrm{Ahmed}^{23}$ and Whitson ${ }^{24}$.

The normal boiling point in $\mathrm{R}$, and the mixture molecular weight are given by:

$$
\begin{aligned}
& T_{b}=3540.53-385.934312 \frac{1}{\gamma_{o, R}}-5431.82548 \times \gamma_{o, R}+4193.44761 \times \gamma_{o, R}{ }^{3} \\
& M W_{m}=64.611 \times \exp \left(0.0022 \times T_{b}\right)
\end{aligned}
$$


Once these two properties were obtained the critical pressure $P_{c m}$ was obtained using the Riazi-Daubert ${ }^{25}$ correlation, while the $T_{c m}$ was calculated using the following relationship:

$$
T_{c m}=24.2787 \times T_{b}^{0.58848} \times \gamma_{o, R}^{0.3596}
$$

We observed that the critical pressure, $P_{c m}$, was not always monotonic as the oil became heavier. Particularly for lighter oils, $P_{c m}$ went through a maximum and it decreased at the later stages of depletion. Since we wanted to generalize the equation for heavier and lighter oils, we selected $V_{c m}$ as the correlating variable since it increases monotonically as the oil becomes heavier. The correlation used for $V_{c m}$ was also from Riazi-Daubert ${ }^{25}$.

If the hydrocarbon mixture had a larger percentage of aromatic compounds, the correlation for the molecular weight and normal boiling points would have to be modified. For example, the molecular weight of an aromatic component with a $T_{b}$ of $640^{\circ} \mathrm{F}$ is about $179 \mathrm{lb} / \mathrm{lb}-\mathrm{mol}$, while the same boiling point corresponds to a paraffinic mixture with average molecular weight of about $260 \mathrm{lb} / \mathrm{lb}-\mathrm{mol}$.

The database was screened for consistency following and automated scheme shown above. The method screens for outliers in a given data set and discards the viscosity points that do not follow a consistent pattern, i.e. viscosity should increase monotonically as the pressure decreases.

In conclusion oil viscosity is calculated using,

$$
\begin{aligned}
& \mu_{m}(P, T)=\left(\frac{T \times T_{c m}}{T_{\mathrm{cC} 10}{ }^{2}}\right)^{1.0286}\left(\frac{V_{c m}}{V_{\mathrm{c} 10}}\right)^{0.9841}\left(\frac{R_{s} \times \gamma_{o, R}}{R_{s b}}\right)^{-0.1362 \gamma_{o, R}}\left(\frac{M W_{m}}{M W_{\mathrm{C} 10}}\right)^{-3.9243} R_{s b}{ }^{-0.4471} A P I^{-2.2902} \\
& \quad \times \exp \left(-0.2606 \times\left(\frac{B_{o}}{B_{o b}}\right)^{3}-0.02359 \frac{P \times V_{c m}}{T_{\mathrm{C} 10}}+2.1388 \frac{\rho_{\mathrm{c} 10}}{\rho_{c \mathrm{C} 10}}+0.1930 \mu_{\mathrm{c} 10}\left(P_{o}, T_{o}\right)\right)
\end{aligned}
$$

where $B_{o}$, the formation volume factor, is dimensionless, $\gamma_{o, R}$ is the specific gravity of oil at reservoir conditions, $A P I$ is the gravity of the oil at standard conditions, $R_{s}$ is the solution gas/oil ratio in SCF/STB (standard cubic feet per stock tank barrel). $R_{s b}$ and $B_{o b}$ are evaluated at the bubble point pressure. 
The advantage of this model is that it can be easily retuned if necessary using linear regression. The exponent for the variable $\left(B_{d} / B_{o b}\right)$ was determined independently and it is left as a fixed parameter. The n-decane density and viscosity were evaluated at the same reference pressure and temperature indicated in Eqns. (13) and (14), and the same values for $\alpha_{m}$ and $\alpha_{o}$ defined in Eqns. (11) and (12) were used. No attempt was made to retune these values.

\section{Results}

Our model was developed using a data set of 2,343 points (Data Set 1) and it was validated with an independent data set from Core laboratories consisting of 150 observations (Data Set 2). Table 3 indicates the ranges of viscosity, temperature, and pressure for the two sets.

To evaluate the performance of this model we selected two different models. These models do not assume the knowledge of the dead-oil viscosity. Khan et al. ${ }^{4}$ proposed a correlation for the bubble point viscosity, while Petrosky ${ }^{9}$ proposed a correlation for the dead-oil viscosity. The experimental ranges of pressure, oil gravity, temperature, and solution-gas/oil ratios are similar to those of our databases.

Figs. 8 and 9 show predicted versus experimental viscosities for Data Set 1 according to Khan's et al. correlation, and to Petrosky's correlation. Fig. 10 shows the performance of the adapted untuned Pedersen model, Eqn. (10) with the original coefficients but using n-decane as the reference fluid, while Fig. 11 shows the predicted versus the experimental viscosity for from this work. Figures 12 to 15 depict the predicted versus experimental viscosities for Data Set 2 according to Khan's et al. correlation, Petrosky's correlation, the untuned Pedersen's model Eqn. 10, and this work respectively.

If the parameters $\alpha_{1}$ to $\alpha_{3}$ from Eqn. 10 are determined for every set, then the fit can be substantially improved as indicated in Fig. 16. Current research efforts seek to generalize the dependence of the parameters $\alpha_{1}$ to $\alpha_{3}$ with ${ }^{\circ} A P I, R_{s b}$ and other field derived variables. Table 4 summarizes the statistics for these models. 


\section{Conclusions}

We presented a new viscosity correlation derived from Pedersen's corresponding states model, which does not require compositional information and can be used for black oil fluids. This model can be easily implemented in any reservoir simulation software, it can be easily tuned, and it provides better estimates of oil viscosity than the existing correlations.

\section{FUTURE WORK}

The next step will be to use a 'pseudo-component' method to characterize compositionally heavy oil samples. A description of this method has been presented in the first report. Some heavy oil samples reported in literature ${ }^{26}$ and others provided by Dr. Rebecca Bryant from Bio-Engineering International will be used in this work. After characterization the viscosity prediction method presented in this work will be modified and applied to the characterized heavy oil samples. A methodology to predict heavy oil viscosity when compositional information is available will be presented. 



\section{NOMENCLATURE}

$\begin{array}{lll}A P I & = & \text { Oil gravity, }\left(\mathrm{API}=145 / \gamma_{o, S T C}-135\right) \\ B_{o} & = & \text { Oil formation volume factor, }(\mathrm{RB} / \mathrm{STB}) \\ B_{o b} & = & \text { Oil Formation Volume Factor at the Bubble-point, } \mathrm{RB} / \mathrm{STB} \\ M W_{m} & = & \text { Mixture molecular weight } \\ P_{c m} & = & \text { Mixture critical pressure (psia) } \\ P & = & \text { Pressure (psia) } \\ P_{b} & = & \text { Bubble-point pressure,psia } \\ P_{r} & = & \text { Reduced pressure,p/pb } \\ R_{s} & = & \text { Solution Gas/Oil Ratio, }(\mathrm{SCF} / \mathrm{STB}) \\ R_{s b} & = & \text { Solution gas-oil-ratio at the bubble-point, }(\mathrm{SCF} / \mathrm{STB}) \\ R_{s r} & = & \text { Reduced solution gas-oil ratio, } \mathrm{Rs} / \mathrm{Rsb} \\ T & = & \text { Reservoir Temperature, }\left({ }^{\circ} \mathrm{F}, \mathrm{R}\right) \\ T_{c m} & = & \text { Mixture critical temperature }(\mathrm{R}) \\ V_{c m} & =\quad \text { Mixture critical volume, }(\mathrm{ft} / \mathrm{lbmol}) \\ \gamma_{o, R} & =\quad \text { Oil specific gravity at reservoir conditions } \\ \rho & \left.=\quad \text { Density (lb/ } \mathrm{ft}^{3}\right) \\ \alpha_{m} & =\quad \text { parameter defined in Eqn. }(11) \\ \alpha_{o} & =\quad \text { parameter defined in Eqn. }(12) \\ \mu & =\quad \text { Oil viscosity, cp }\end{array}$

\section{Subscripts}

$\begin{array}{lll}o & = & \text { reference conditions, oil } \\ c 10 & = & \text { n-decane. } \\ r & = & \text { reduced } \\ c & = & \text { critical } \\ m & = & \text { mixture } \\ b & = & \text { at bubble point, or normal boiling point (Eq. 8). } \\ o, R & = & \text { oil at reservoir conditions } \\ g, 100 & = & \text { gas at } 100 \text { psia. }\end{array}$





\section{REFERENCES}

[1] K. S Pedersen,. A. Fredenslund, P. L. Christensen and P. Thomassen, Chem. Eng. Sci. 39, (1984) 1011-1016.

[2] Butler, R. M. "Thermal Recovery of Oil and Bitumen," Prentice-Hall Inc., New Jersey, 1991.

[3] Willman, B.T. "Laboratory Studies of Oil Recovery by Steam Injection," J.Pet. Tech. (July 1961) 681-698.

[4] J.Lohrenz, B.G Bray, and C. R. Clark, J. Pet. Technol., Oct. 1964 - 1171

[5] J. Chew, and C. A., Connally, Jr., Trans. AIME (1959) Vol. 216, 23-25.

[6] H. D Beggs,.and J. R Robinson, J. Pet. Tech. (Sept., 1975) 1140-1141.

[7] S. A. Khan, M.A. Al-Marhoun, and S.O. Duffuaa, SPE 15720, (1987).

[8] R.S. Kartoatmodjo, and Z. Schmidt, Oil and Gas J. (1994), 51-55.

[9] G.E. Petrosky, and F.F. Farshad, SPE 29468, (1995).

[10] J. F. Ely, and H.J.M. Hanley, Ind. Eng. Chem. Fundam_20, (1981a) 77-81.

[11] K.S. Pedersen, and A. Fredenslund, Chem. Eng. Sci., 42, (1987), 182-186.

[12] W.D. Monnery, A.K. Mehrotra, and W. Y. Svrcek, Can. J. Chem. Eng. 69 (1991) 1213-1217.

[13] F. O. Reudelhuber.: "Sampling Procedures for Oil Reservoir Fluids," J. Pet. Tech. (Dec 1957), 9, 15-18.

[14] W. D. McCain, Jr.: The Properties of Petroleum Fluids, Second Ed., Pennwell Publishing Co., Tulsa, OK (1990).

[15] Henley, H. J. M., R. D. McCarty and W. M. Haynes, Cryogenics, July, 413-415 (1975).

[16] Tham, M. J. and K. E. Gubbins, J. Chem. Phys., 55, 268-279 (1971). 
[17] Pedersen, K. S. and A. Fredenslund, Chem. Eng. Sci., 42, 182-186 (1986).

[18] R. D. McCarty, Cryogenics, (1974) 276-280.

[19] K. C. Mo, and K. Gubbins, Chem. Eng. Commun. 1, (1974) 281-290.

[20] Geopetrole, Viscosity and Density of Light Paraffins, Nitrogen and Carbon Dioxide, Editions Technip-Paris (1970).

[21] SAS language. Version 6. Publisher Cary, NC. SAS Institute, (1990).

[22] W. D. McCain, Jr.: The Properties of Petroleum Fluids, Second Ed., Pennwell Publishing Co., Tulsa, OK (1990).

[23] T. Ahmed, Hydrocarbon Phase Behavior, Gulf Publishing Co. $1^{\text {st }}$ Ed. (1990).

[24] C. H. Whitson, SPE J, August (1983), 683-694.

[25] M. R. Riazi and T. E. Daubert, I \& EC Res. 26, (1987) 755-759.

[26] Pedersen, K. S., Data provided upon request (2000). 


\section{TABLES AND FIGURES}

Table 1. Differential Vaporization Test at $80^{\circ} \mathrm{F}$.

\begin{tabular}{|c|c|c|c|c|c|c|}
\hline $\begin{array}{l}\text { Pressure } \\
\text { (psig) }\end{array}$ & $\begin{array}{l}\boldsymbol{R}_{S}{ }^{[I]} \\
(S C F / \\
S T B)\end{array}$ & $\begin{array}{l}B_{o}{ }^{[2]} \\
(R B / \\
S T B)\end{array}$ & $\begin{array}{l}\text { Oil } \\
\text { Density } \\
\rho_{o} \\
(\mathrm{gm} / \mathrm{cc})\end{array}$ & $\begin{array}{l}\text { Gas } \\
\text { Deviation } \\
\text { Factor } \\
Z\end{array}$ & $\begin{array}{l}\mathrm{Bg}^{[3]} \\
(R C F / \\
S C F)\end{array}$ & $\begin{array}{l}\text { Gas } \\
\text { Gravity } \\
\gamma_{g}\end{array}$ \\
\hline 1690 & 210 & 1.069 & 0.9022 & & & \\
\hline 1500 & 188 & 1.063 & 0.9052 & 0.822 & 0.00825 & 0.581 \\
\hline 1300 & 165 & 1.056 & 0.9083 & 0.835 & 0.00966 & 0.576 \\
\hline 1100 & 141 & 1.049 & 0.9113 & 0.852 & 0.01162 & 0.573 \\
\hline 900 & 117 & 1.042 & 0.9143 & 0.872 & 0.01450 & 0.571 \\
\hline 700 & 93 & 1.036 & 0.9174 & 0.896 & 0.01906 & 0.572 \\
\hline 500 & 68 & 1.029 & 0.9205 & 0.922 & 0.02724 & 0.574 \\
\hline 300 & 42 & 1.022 & 0.9235 & 0.951 & 0.04593 & 0.581 \\
\hline 100 & 15 & 1.014 & 0.9268 & 0.983 & 0.13004 & 0.600 \\
\hline 0 & 0 & 1.008 & 0.9305 & & & 0.724 \\
\hline \multicolumn{7}{|c|}{$\begin{array}{l}\text { Gravity of Residual Oil }=19.2^{\circ} \mathrm{API} @ 60^{\circ} \mathrm{F} \\
\text { [1] Cubic feet of gas at } 14.7 \text { psia and } 60^{\circ} \mathrm{F} \text { per barrel of residual oil at } 60^{\circ} \mathrm{F} \text {. } \\
\text { [2] Barrels of oil at indicated pressure and temperature per barrel of residual oil at } 60^{\circ} \mathrm{F} \text {. } \\
\text { [3] Barrels of oil plus liberated gas at indicated pressure and temperature per barrel of } \\
\text { residual oil at } 60^{\circ} \mathrm{F} \text {. } \\
\text { [4] Cubic feet of gas at indicated pressure and temperature per cubic foot at } 14.7 \text { psia } \\
\text { and } 60^{\circ} \mathrm{F} \text {. }\end{array}$} \\
\hline
\end{tabular}

Table 2. Viscosity Data Accompanying DL Set at $80^{\circ} \mathrm{F}$ and $19.2^{\circ} \mathrm{API}$ Residual Oil.

\begin{tabular}{||l|l|l|l|}
\hline $\begin{array}{l}\text { Pressure } \\
\text { (psig) }\end{array}$ & $\begin{array}{l}\text { Oil Viscosity } \\
(\boldsymbol{c} p)\end{array}$ & $\begin{array}{l}\text { Calculated } \\
\text { Gas Viscosity } \\
(\boldsymbol{c} p)\end{array}$ & $\begin{array}{l}\text { Oil/Gas } \\
\text { Viscosity } \\
\text { Ratio }\end{array}$ \\
\hline $1690\left(P_{b}\right)$ & 35.4 & & \\
\hline 1500 & 40.0 & 0.0146 & 2740 \\
\hline 1300 & 45.2 & 0.0140 & 3230 \\
\hline 1100 & 51.2 & 0.0134 & 3820 \\
\hline 900 & 58.5 & 0.0129 & 4530 \\
\hline 700 & 68.4 & 0.0124 & 5520 \\
\hline 500 & 82.5 & 0.0120 & 6880 \\
\hline 300 & 102.1 & 0.0116 & 8800 \\
\hline 100 & 127.6 & 0.0113 & 11300 \\
\hline 0 & 177.0 & 0.0106 & 16700 \\
\hline
\end{tabular}

Table 3. Range of input data. SI units and values in are indicated in parenthesis. 


\begin{tabular}{|c|c|c|c|c|}
\hline Dataset & $\mathbf{N}^{\mathbf{0}}$ Points. & Variable & Minimum & Maximum \\
\hline$\# 1$ & 2343 & Oil Density: $1 \mathrm{bm} / \mathrm{ft}^{3}\left(\mathrm{~g} / \mathrm{cm}^{3}\right)$ & $35.11(0.562)$ & $57.31(0.92)$ \\
\hline$\# 2$ & 150 & Oil Density, $\mathrm{bm} / \mathrm{ft}^{3}\left(\mathrm{~g} / \mathrm{cm}^{3}\right)$ & $24.31(0.389)$ & $57.50(0.921)$ \\
\hline$\# 1$ & 2343 & Oil Viscosity, $\mathrm{cp}$ & 0.132 & 78.30 \\
\hline$\# 2$ & 150 & Oil Viscosity, $\mathrm{cp}$ & 0.13 & 68.90 \\
\hline$\# 1$ & 2343 & Temperature, $\mathrm{R}(\mathrm{K})$ & $540(300)$ & $766(425.5)$ \\
\hline$\# 2$ & 150 & Temperature, $\mathrm{R}(\mathrm{K})$ & $537(303.9)$ & $762(423.3)$ \\
\hline$\# 1$ & 2343 & Pressure, $\mathrm{psia}(M P a)$ & $14.7(0.1)$ & $5601.7(38.62)$ \\
\hline$\# 2$ & 150 & Pressure, psia $(M P a)$ & $102.7(0.708)$ & $5434.7(37.47)$ \\
\hline
\end{tabular}

Table 4. Summary of the black oil viscosity models performance.

\begin{tabular}{|c|c|c|c|c|}
\hline Model & $\begin{array}{c}\text { Number of } \\
\text { Observations }\end{array}$ & $\begin{array}{c}\text { Maximum } \\
\text { Error, \% }\end{array}$ & $\begin{array}{c}\text { Minimum } \\
\text { Error, \% }\end{array}$ & $\begin{array}{c}\text { Average } \\
\text { Error, \% }\end{array}$ \\
\hline Khan & 2343 & 81.6 & -567 & -28 \\
\hline Khan & 150 & 66.1 & -636 & -60.8 \\
\hline Petrosky & 2343 & 80.1 & -214 & 4.9 \\
\hline Petrosky & 150 & 44.8 & -111 & -1.4 \\
\hline Adapted Pedersen & 2343 & 99.2 & -384. & 62 \\
\hline Adapted Pedersen & 150 & 98.9 & -382 & 54 \\
\hline This Work & 2343 & 77.7 & -317 & 0.9 \\
\hline This Work & 150 & 58.7 & -189 & -0.7 \\
\hline
\end{tabular}




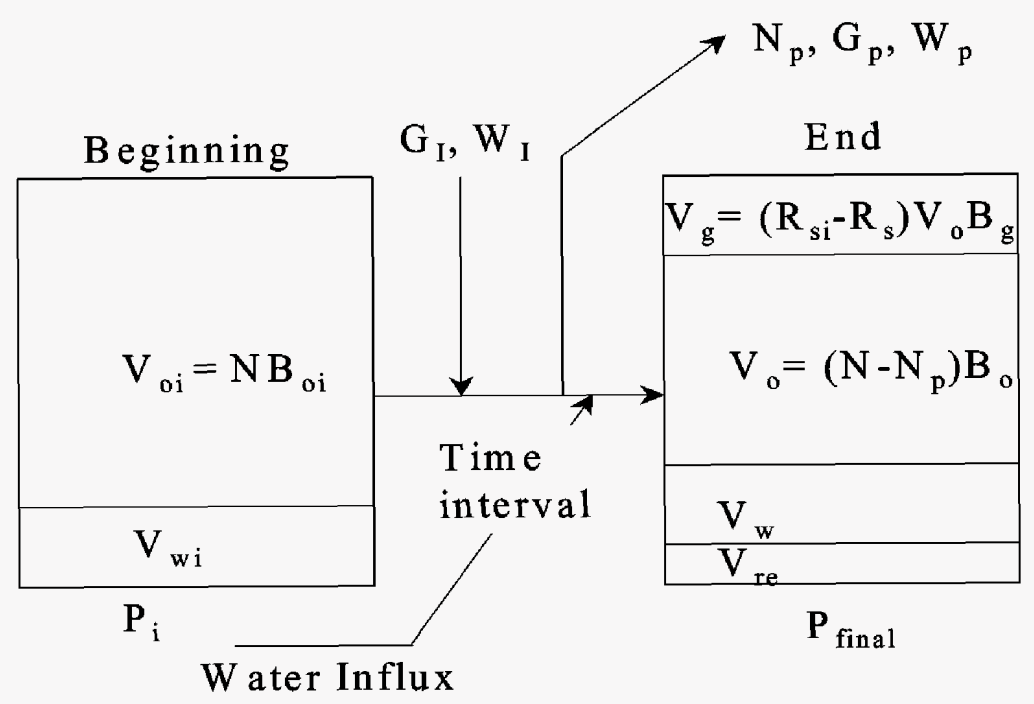

Fig. 1. PVT Properties Used in Material Balance Computations.

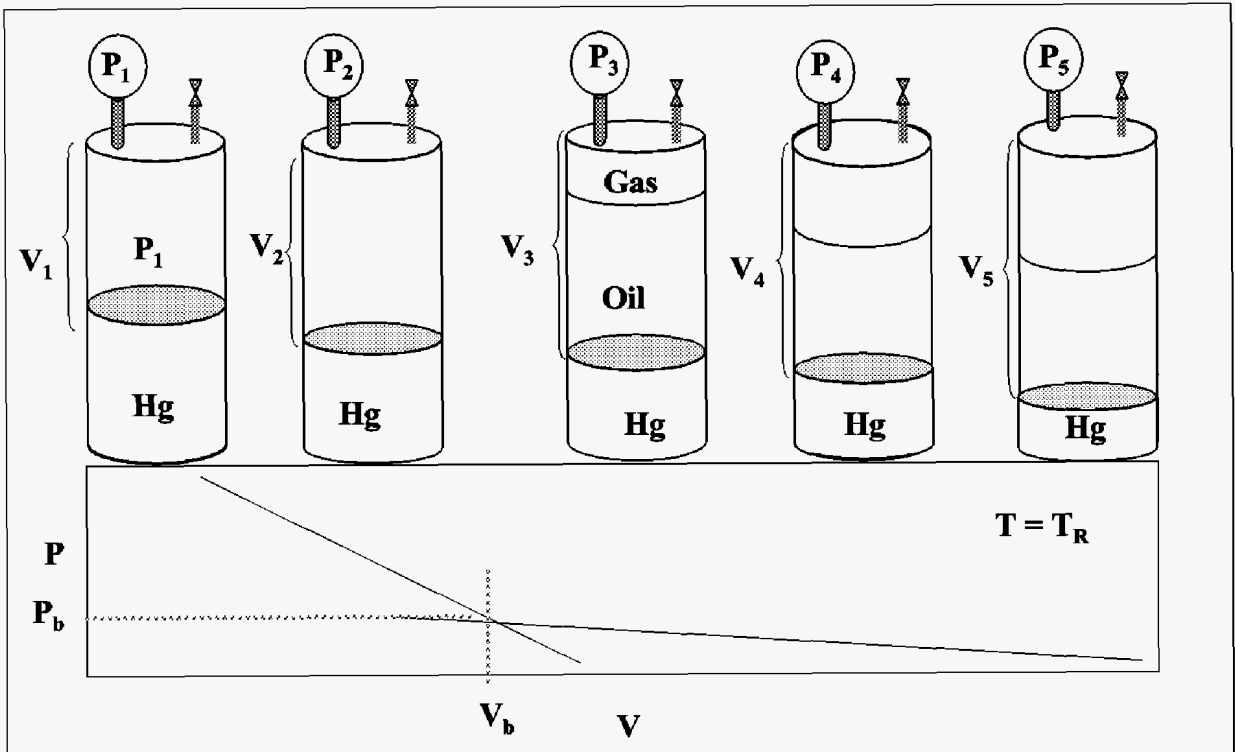

Fig. 2. Crude Oil Constant Composition Expansion Test. 


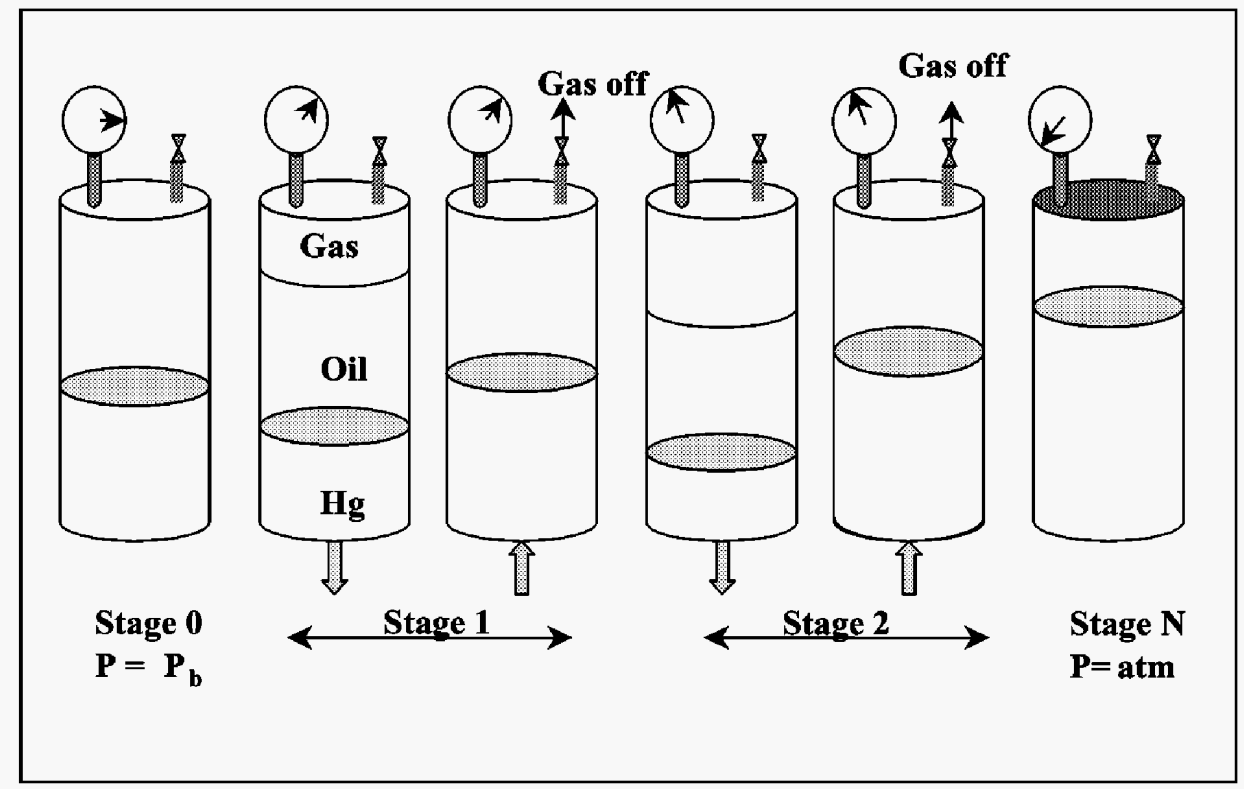

Fig. 3. Crude Oil Differential Liberation Test.

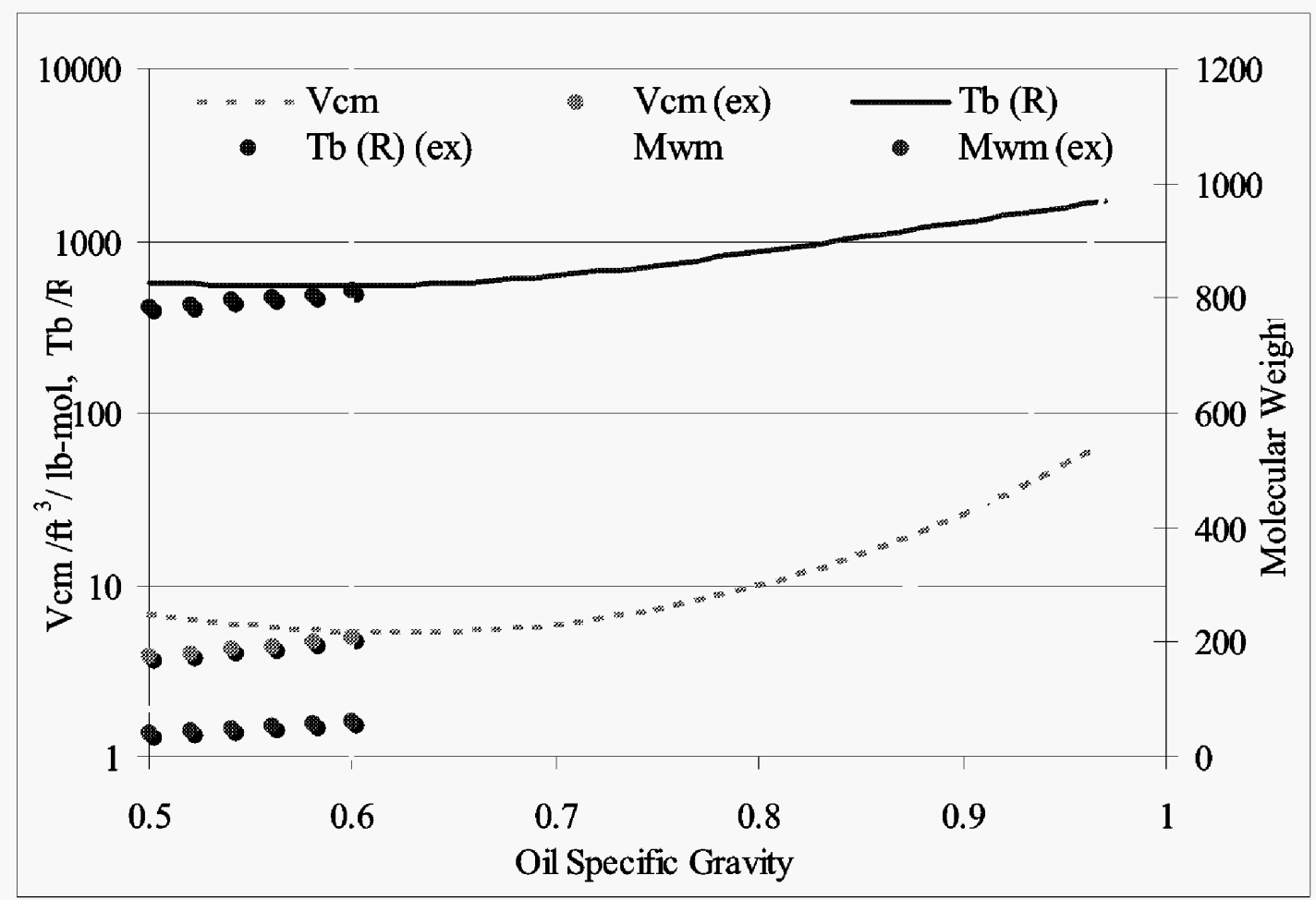

Fig. 4. Pseudo-critical Volume $\left(V_{c m}\right)$, Mixture Molecular Weight $\left(M_{w m}\right)$ and Normal Boiling Point $\left(T_{b}\right)$ as a Function of Oil Specific Gravity. 


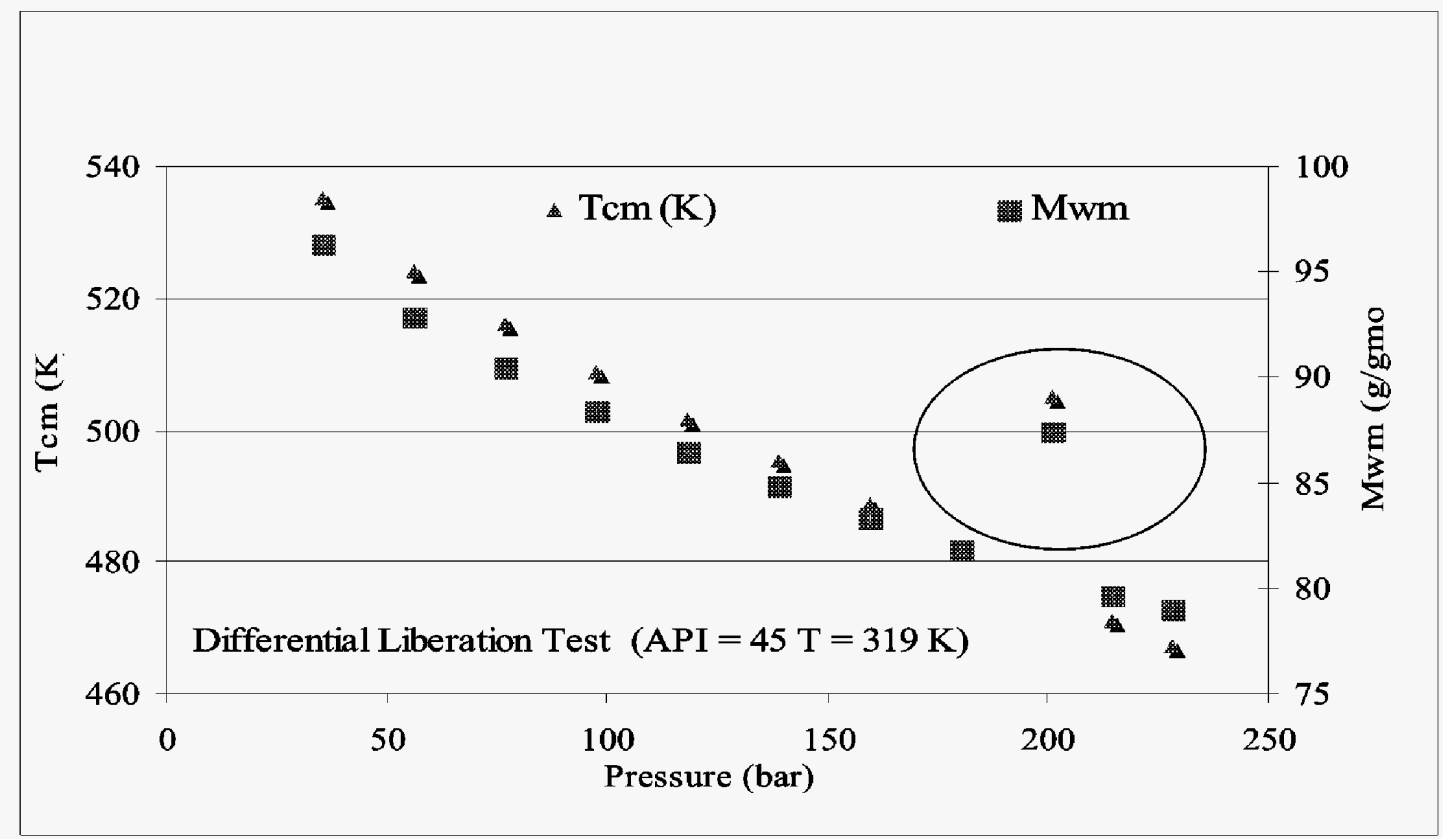

Fig. 5. Removed Data at $\mathrm{P}=200$ Bar Due to Inconsistent Physical Trend.

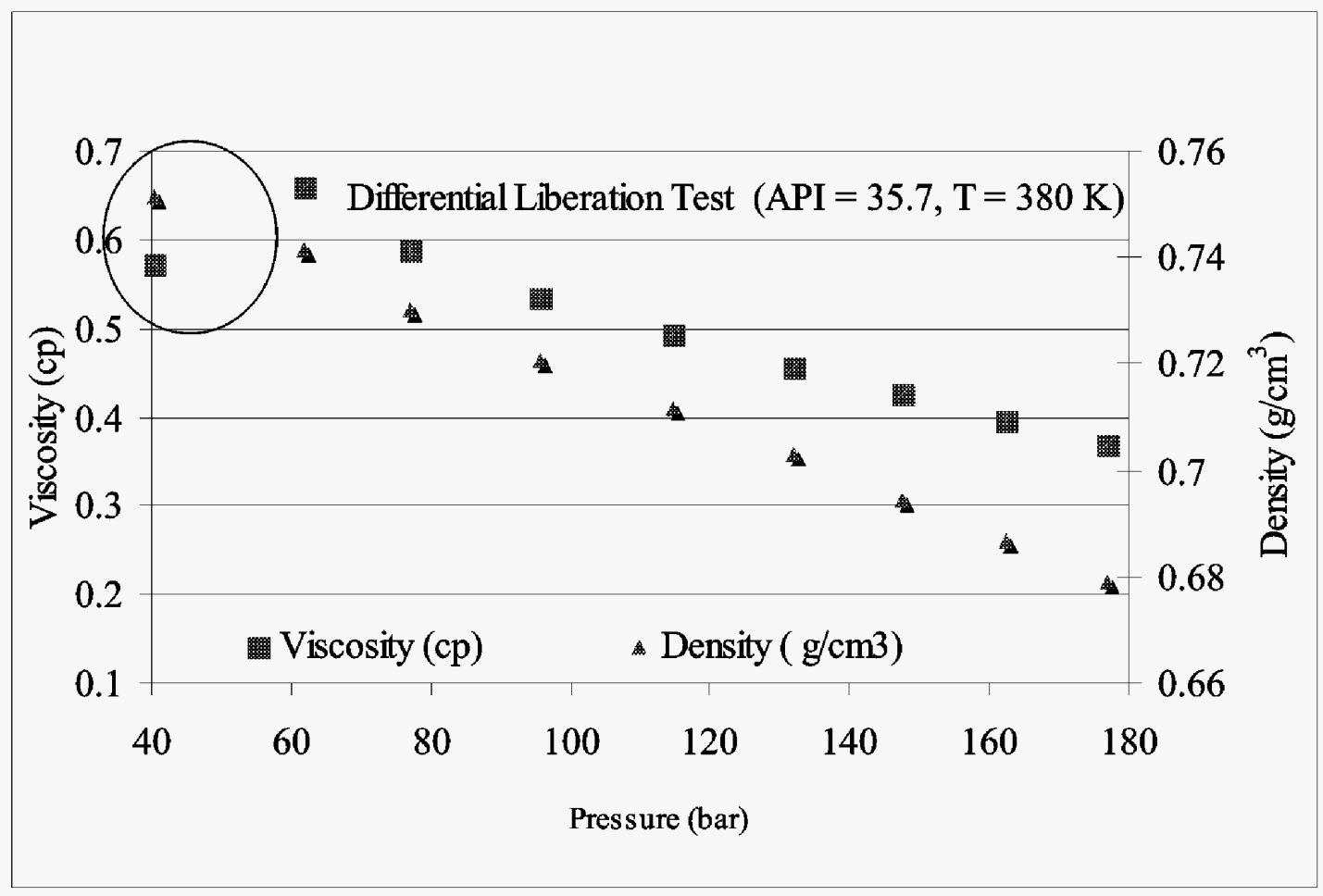

Fig. 6. Removed End Point Viscosity. Violation of Monotonic Behavior. 


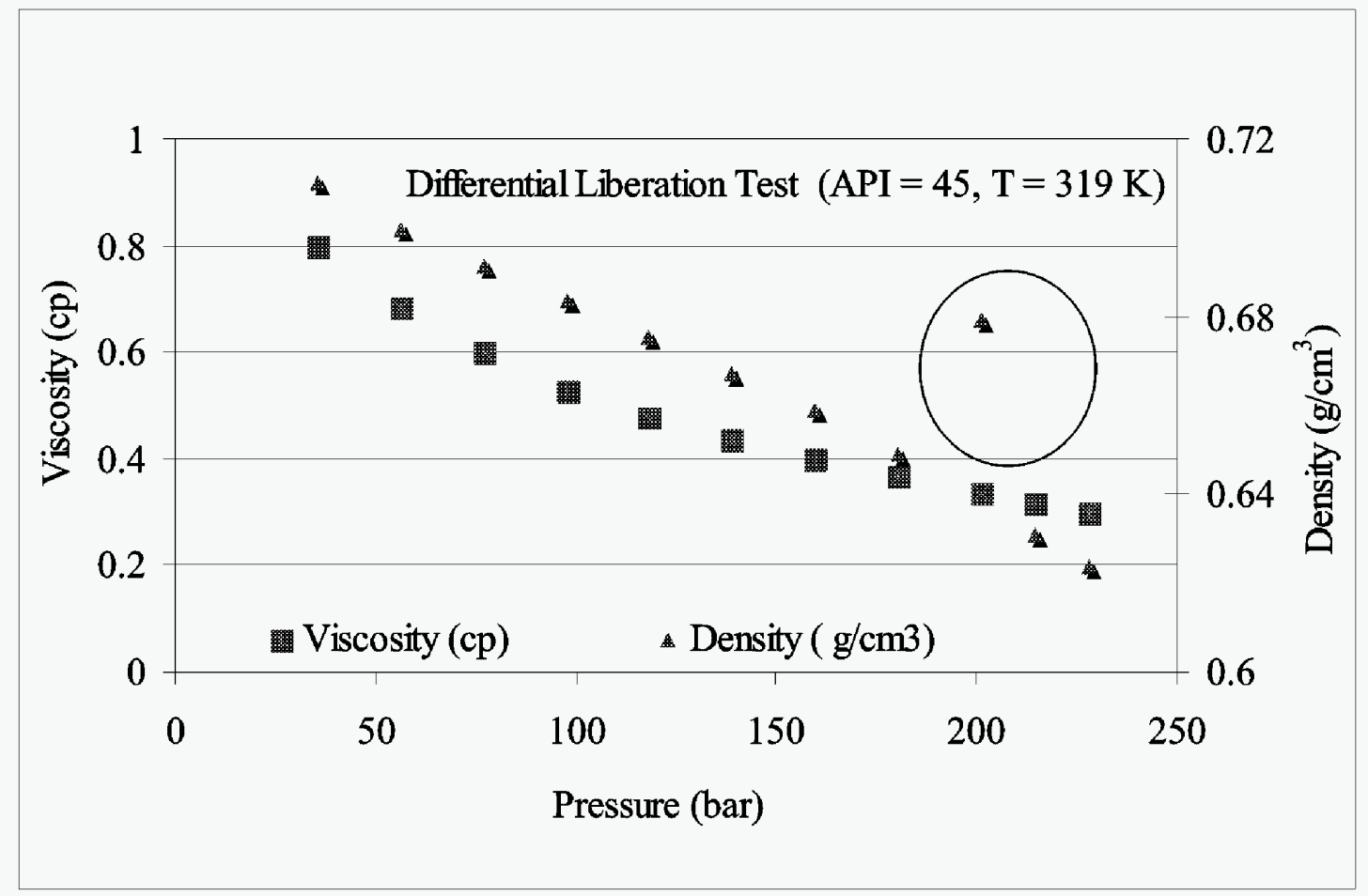

Fig. 7. Removed Oil Density at $P=200$ Bar Due to Inconsistent Trend.

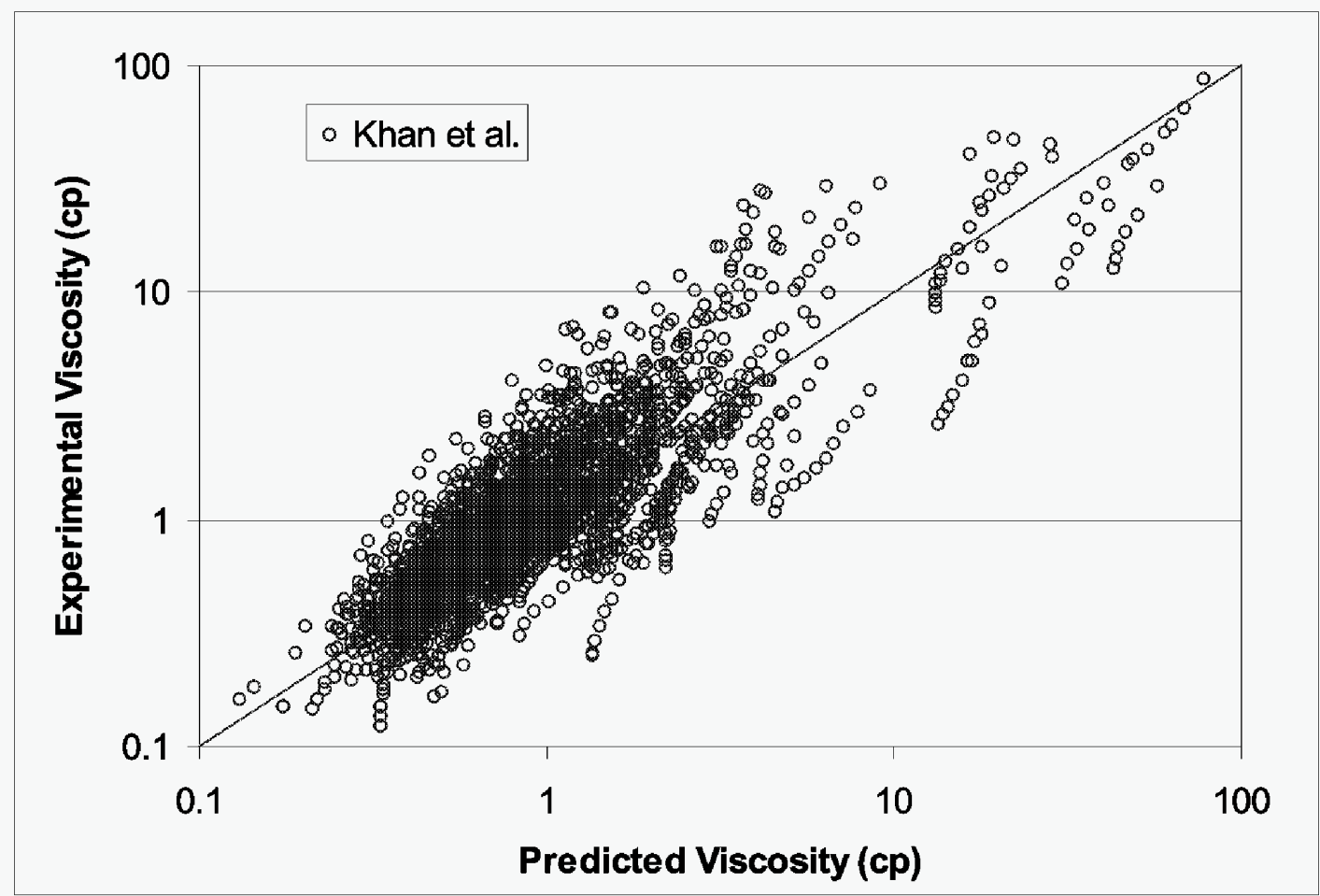

Fig. 8. Predicted Viscosity vs. Experimental Viscosity - Khan et al. model (Data Set 1) 

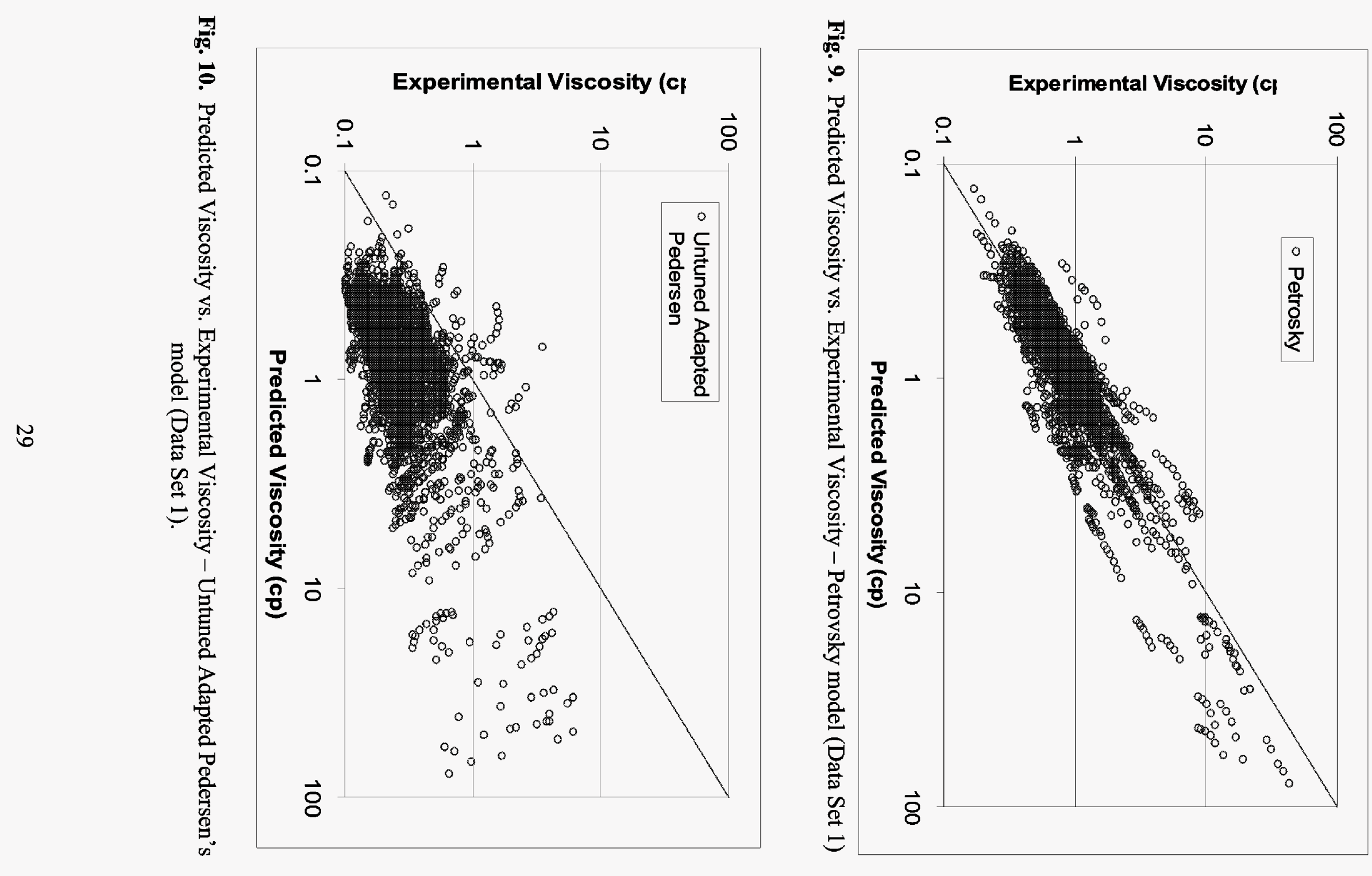

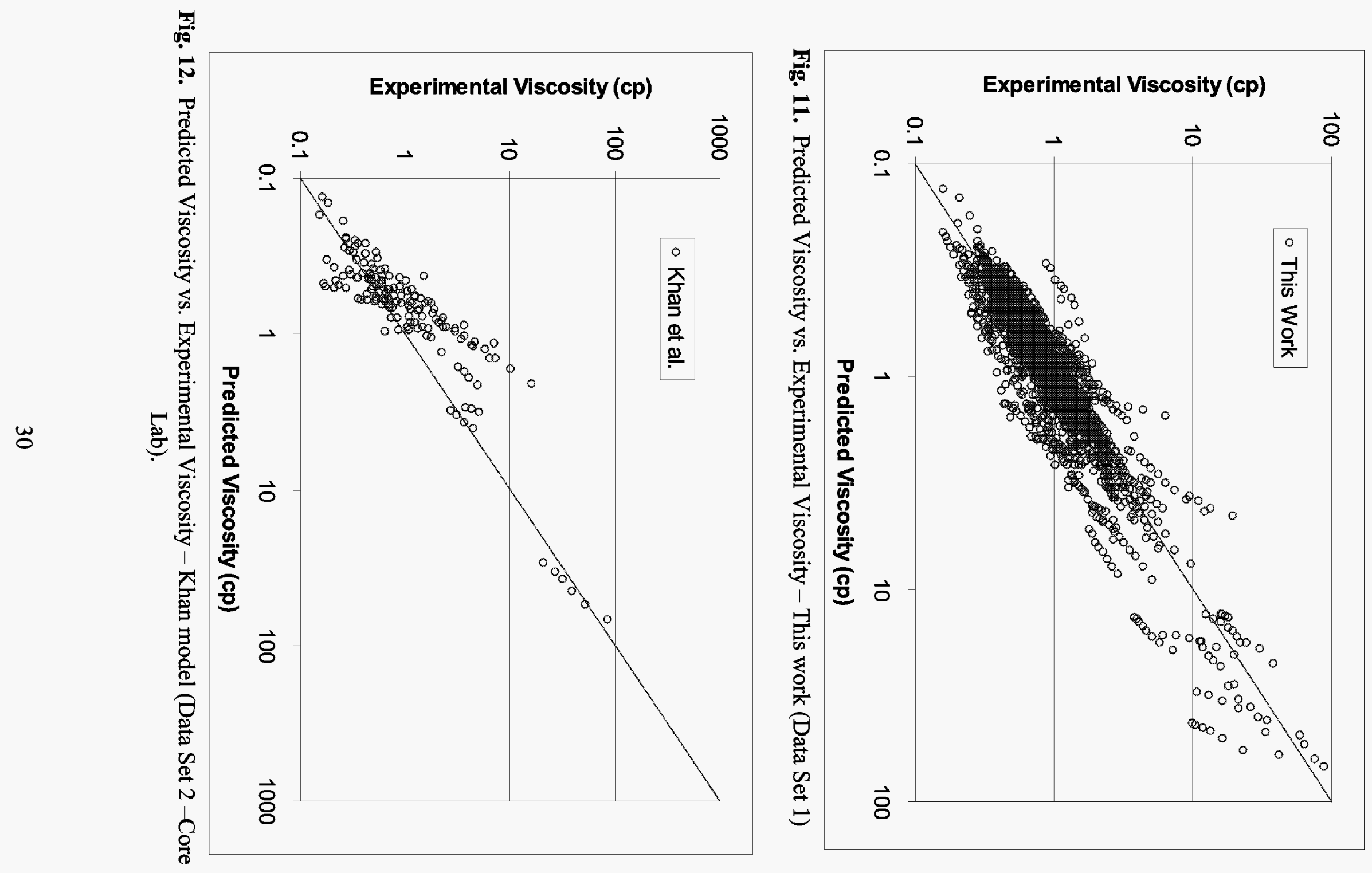

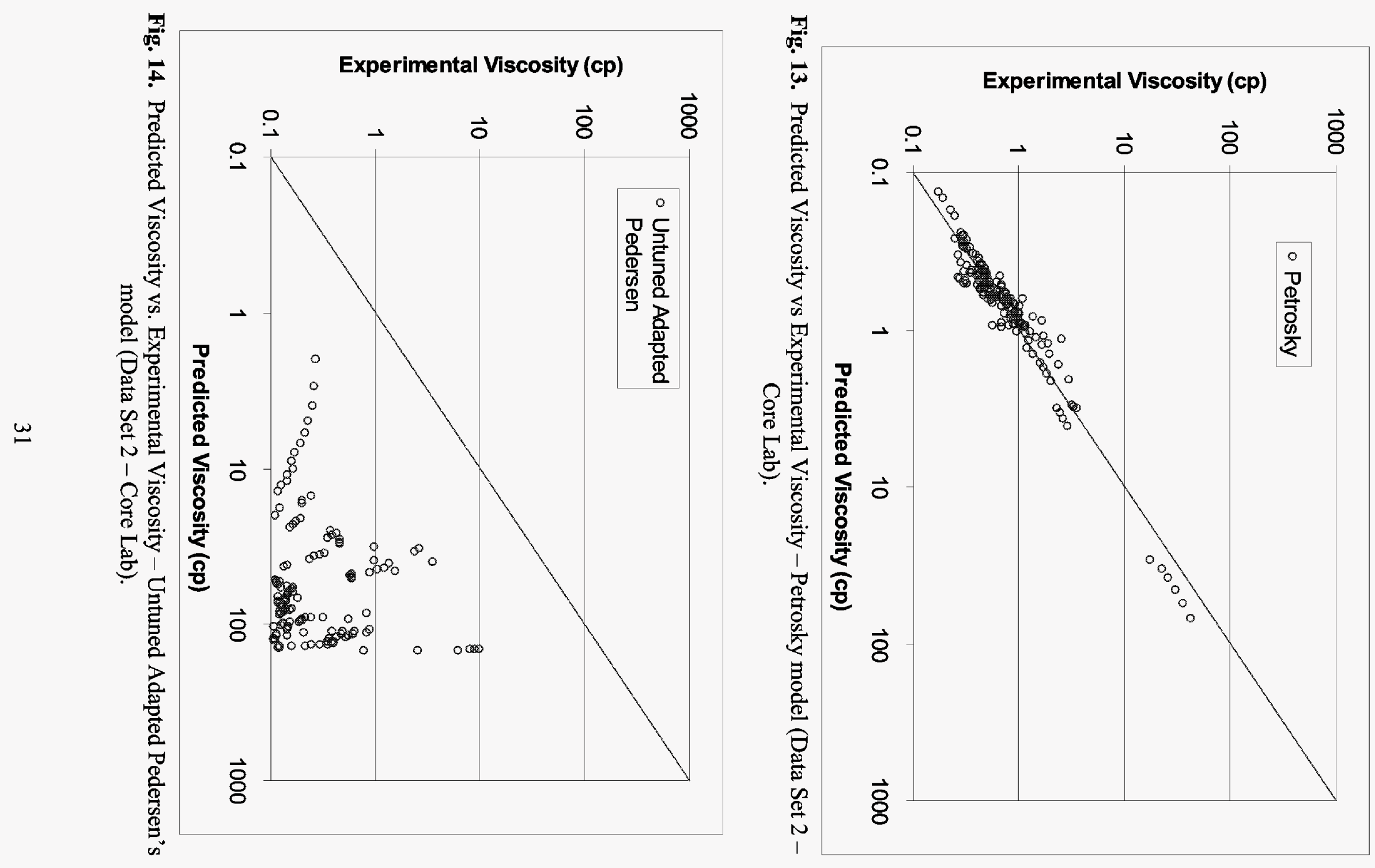


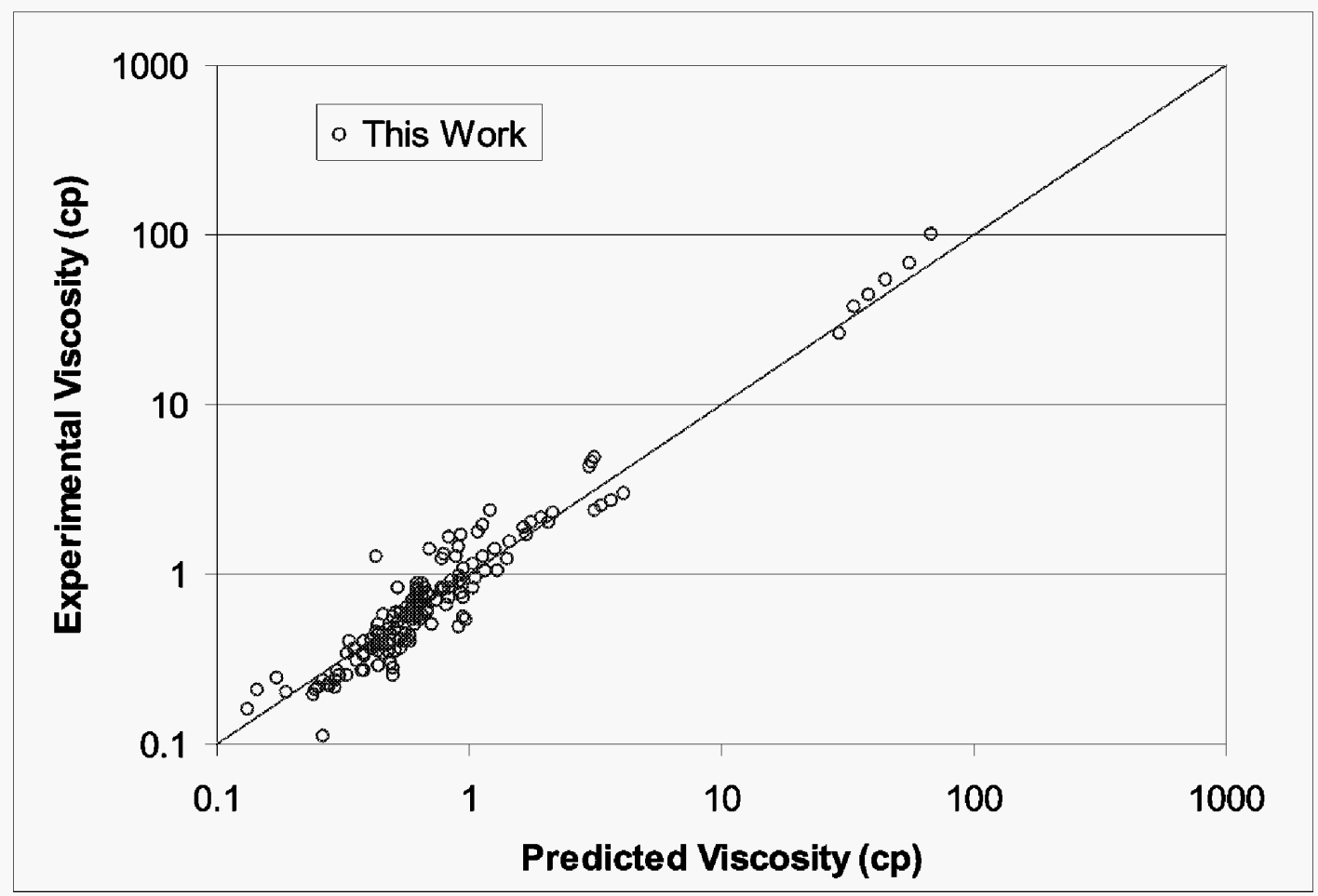

Fig. 15. Predicted Viscosity vs. Experimental Viscosity - This work (Data Set 2 - Core Lab).

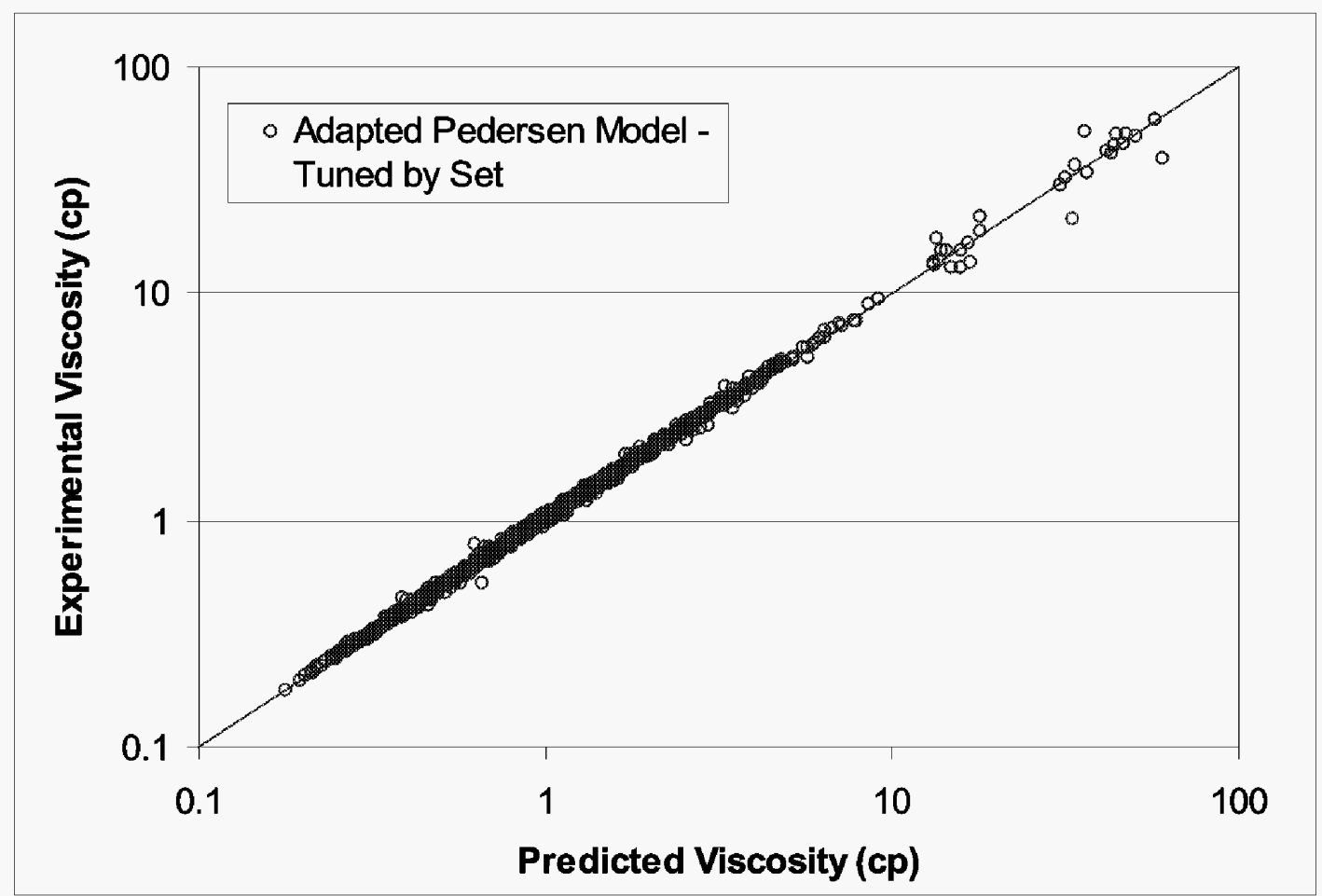

Fig. 16. Predicted Viscosity vs. Experimental Viscosity - Adapted Pedersen's Model tuned per set. 
